\title{
Flirting with reality
}

Unruly Complexity: Ecology, Interpretation, Engagement by Peter J. Taylor. The University of Chicago Press, 2005. £38.00/£16.00 hbk/pbk (289 pages) ISBN $0226790355 / 00226790363$

\section{Jordi Bascompte}

Integrative Ecology Group, Estación Bioló gica de Doñana, CSIC, Apdo. 1056, Sevilla 41080, Spain

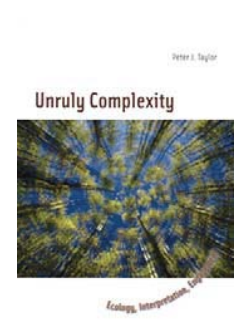

As scientists, we face the challenge of describing and interpreting nature, a difficult task given that nature rarely answers our questions clearly. We need to sort out this lack of clear answers by integrating pieces of information taken from different sources and by using creative approaches. And we have to become aware of the boundaries and limitations of our endeavours. In Unruly Complexity,

Peter Taylor presents a personal account of how our interpretations are influenced by our own approaches and social practices.

Taylor's tale follows the path of two brilliant biologists, Richard Levins and Richard Lewontin, who, two decades ago, made the case that science is a social process that both causes and is caused by social organization [1]. Taylor's book is more like a road map describing how his own personal scientific practice led him to the same conclusion. Unruly Complexity is an interdisciplinary travel through the domains of truth, interpretation and metaphors. It is certainly an honest exercise, a critical questioning of the openness of our systems of study. Taylor uses examples from his own work ranging from theoretical ecology to socio-environmental research and one central element in his story is that scientist cannot fully isolate their system of study from their own personal practices. Scientists, thus, are embedded within social networks whose structure greatly affects the outcome of the scientific process. The diary-like style of the book, reflecting the author's own scientific maturation, has the advantage of providing a first-hand account, although as all personal trips, it is a convoluted one, which, for good or bad, is reflected in the structure of the book. The reader might perceive at least three different angles or stories each with somehow differential levels of detail.

The first part of Unruly Complexity revolves around the question of simplifying ecological complexity, and Levin's tradeoff between generality, precision and realism is still a valid statement of the limitations of any model [2]. Theory provides simple cartoons, the 'perfect crystals' of ecology [3]. These simple models offer insight that helps in interpreting the incomplete message from nature. But in crafting such cartoons, as with any creative enterprise, theoreticians also search aesthetics. This was explicitly acknowledged by the physicist Hermann Weyl, who told

Corresponding author: Bascompte, J.D (bascompte@ebd.csic.es)

Available online 30 March 2006. that his work 'always tried to unite the true with the beautiful; but when I had to choose one or another, I usually chose the beautiful' [4].

A similar example is the use of metaphors to represent complex ecosystems. Here, Taylor chooses a wonderful example, H.T. Odum's energy flow diagrams as analogies of electrical circuits. This type of representation of communities has implicit personal interpretation. It implies choosing a level of detail while denying others; focusing on flows more than on nodes; neglecting a temporal or spatial dimension. All this is necessary to look for general patterns, but one has to be self-aware of these personal choices. Metaphors and pictorial representations such as Odum's energy flow diagrams pervade science. Although Taylor is mainly concerned by the constraints of visual imagery, this has often had a causal role in scientific creativity. There is no better example than Einstein's thought experiments enabling him to interpret a mathematical theory as a theory of space and time [5].

Taylor's story follows by considering how the social networks in which scientists are embedded constrain the approaches to complex issues in socio-environmental research. Using his experience organizing workshops, he provides particular informed examples where scientists were confronted by the task of thinking about how their choices and limitations affect their conclusions. This is an interesting experience, although the point is made early on and the reader might feel that too much emphasis is put on a few examples.

Overall, Unruly Complexity is a brave account of the subtle difficulties of relating truth and interpretation. It will certainly stimulate the reader to consider the openness of his or her system of study and to think of interpretation not as a direct transfer from nature to a passive receptor, but as a stimulating creative enterprise in which social systems and personal views shape and constrain our view of nature. Accepting such limitations is not by any account denying the value of science to understand nature. On the contrary, it makes science a creative, beautiful enterprise. As David Hull once wrote, 'Science is not a perfect machine for grinding out true claims about the world in which we live, but it is the best of all the imperfect machines developed to date' [6].

\section{References}

1 Levins, R. and Lewontin, R. (1985) The Dialectical Biologist. Harvard University Press

2 Levins, R. (1966) The strategy of model building in population biology. Am. Sci. 54, 421-431 
3 May, R.M. (1973) Stability and Complexity in Model Ecosystems. Princeton University Press

4 Chandrasekar, S. (1987) Truth and Beauty: Aesthetics and Motivations in Science. The University of Chicago Press

5 Miller, A.I. (1996) Insights of Genius: Imagery and Creativity in Science and Art. Springer-Verlag
6 Hull, D.L. (1988) Science as a Process: An Evolutionary Account of the Social and Conceptual Development of Science. The University of Chicago Press

0169-5347/\$ - see front matter (c) 2006 Elsevier Ltd. All rights reserved. doi:10.1016/j.tree.2006.03.009

\section{Searching for sustainability}

Sustainability: A Philosophy of Adaptive Ecosystem Management by Bryan G. Norton. University of Chicago Press, 2005. US\$90.00/US\$37.50 hbk/pbk (608 pages) ISBN 022659519 6/0 226595218

\section{Andrew Watkinson ${ }^{1,2}$}

${ }^{1}$ School of Environmental Sciences, University of East Anglia, Norwich, UK, NR4 7TJ

${ }^{2}$ The Tyndall Centre for Climate Change Research, University of East Anglia, Norwich, UK, NR4 7TJ

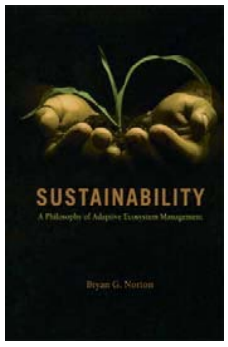

I found Sustainability to be a frustrating book. Most readers will be familiar with the definition of sustainability provided in the Brundtland Report [1]. However, it is not until p. 363 of Sustainability that Bryan Norton provides his definition of sustainability as '... a relationship between generations such that the earlier generations fulfil their individual wants and needs so as not to destroy, or close off, important and valued options for future generations'.

This definition is yet another variant of a multitude of similar definitions. Yet Norton claims 'to develop a new interdisciplinary approach to defining sustainability, using philosophical and linguistic analyses to create a nonidealogical vocabulary that can accommodate scientific and evaluative environmental discourse'. However, these analyses, although often interesting, do not lead to greater clarity in the definition of sustainability itself or in indications of how the concept can be more usefully applied. There is, for example, an exploration of the concept of intergenerational obligations, with the author stressing that we cannot guess what people will want in the future or compare their riches to ours. His solution is to place the emphasis on opportunity freedom: the maintenance of options that are essential for fulfilling the aspirations of a community.

How one does this is unclear. There is rather little in the book that enables a pragmatic approach to the question of sustainability. Readers wanting that would, for example, be better visiting the website of the UK Sustainability Commission (http://www.sustainable-development.gov.uk/ index.asp), where an attempt is made to identify what is meant by sustainability from a practical policy perspective and how the pathway to sustainability can be identified through monitoring indicators. This represents a UK perspective, but then, as Norton argues, sustainability values should be specified by the community, which will

Corresponding author: Watkinson, A. (a.watkinson@uea.ac.uk)

Available online 30 June 2006. inevitably lead to key details of a sustainable lifestyle being idiosyncratic to a particular community.

The question of sustainability is not, however, the only theme of Sustainability. In the Introduction, Norton states that 'The book is my best effort to understand and illuminate this problem of failure in public and bureaucratic communication'. Consequently, much of it is concerned with the language of communication, epistemology, values and the decision-making process as it relates to policy making within an environmental context. There are two points I would make here.

First, on account of Norton's expressed frustrations with the environmental decision-making process in the US Environmental Protection Agency, the book has an unashamedly US perspective, which is perhaps why I found it difficult to engage with. Nevertheless, the author has little to say about environmental decision making as it relates to the current Bush administration and there is no climate change entry in the index, despite it being a key issue for sustainability science. Moreover, Norton's criticism of the reluctance of ecologists to become engaged in debates about values and policy does not match my experience with academics in the Ecological Society of America.

Second, Norton makes much of the problem of communication and the issue of language as a barrier to communication. For those of us who work in an interdisciplinary context, this is undoubtedly true, and Norton has some interesting points to make. Yet the language he uses is unashamedly set within social science and philosophical norms. There is no allowance for scientists and engineers trying to come to grips with questions relating to sustainability and the decision-making process or indeed, for that matter, to policy makers. That appears not to be the audience with whom Norton is trying to engage.

Despite these concerns, there is insightful discussion into questions relating to sustainability and decision making. I would highlight the sections on the advantages of the analytical deliberative as opposed to the serial approach to decision making. This is in part because it resonates with my own recent experiences with the UK Government in relation to the question of future flooding, where the policy 